\title{
Labour market flows: November 2011 (Experimental Statistics)
}

\author{
Author Name(s): Marina Wright
}

\begin{abstract}
These estimates of labour market flows are experimental statistics which have been produced as an aid to understanding the movements in the published Labour Force Survey aggregate estimates. They do not have National Statistics status and are not suitable as labour market indicators in their own right. The official LFS estimates are published in the monthly Labour Market Statistical Bulletin.
\end{abstract}

\section{Labour Market Flows}

\section{Background}

In the Labour Force Survey (LFS) respondents are interviewed for five consecutive quarters over a 12 month period, with 20 per cent of the sample being replaced at each quarter. This allows for a longitudinal dataset to be created over a limited time interval, where respondents' characteristics can be tracked over their time in the survey.

The ONS publishes population-weighted longitudinal datasets for each calendar quarter. These are available for each quarter since 1997 and can be used to analyse changes in labour market characteristics over two or five quarters. The datasets include "flow" variables, which estimate the size of the movements between the three main labour market statuses of employment, unemployment and economic inactivity.

Monitoring changes in the labour market status of respondents to the LFS aids the understanding of the quarterly changes in the levels of employment, unemployment and economic inactivity. These indicators are published as stocks for a given period, with changes expressed as the difference between successive quarters. These quarterly comparisons represent the net changes between the three labour market statuses. The underlying gross flows are usually considerably larger and may not correspond with those implied by the net changes. Estimates of the gross flows between the statuses can be derived from the LFS Longitudinal Datasets and are summarised in this note.

\section{Method}

There are two types of LFS longitudinal datasets: two-quarter and five-quarter. These are weighted using the same population estimates as those used in the main quarterly LFS datasets, although 
the weighting methodology differs (see technical note). Consequently the estimates are broadly consistent with the published aggregates, but not entirely. Also, the datasets are limited to people aged 16-64.

Both types of dataset contain a flow variable with eleven categories, with all combinations of employment, unemployment and economic inactivity accounted for, plus two categories for those entering and leaving the 16-64 population over the quarter. For the purpose of this analysis, those entering or leaving this population are excluded from the measured sample. The stock of the employed, unemployed and inactive at each quarter can therefore be estimated by summing the corresponding flow categories.

For this analysis, the two-quarter datasets have been used in order to gain some insight into the quarterly changes in the headline published aggregates. Also, the sample is more robust and less subject to sampling variation than the five-quarter counterparts (see technical note).

\section{The charts provided}

The charts in this briefing note show the estimated gross flows, that is the total inflow or outflow for 16-64 employment, unemployment and inactivity from one calendar quarter to the next. They are not seasonally adjusted. Analysis of the net flows, that is the difference between the total inflow and outflow, are also included and these are compared with the quarterly changes in the published aggregates, partly to give an indication of the robustness of the flows analysis.

\section{Key messages:}

There are large flows between each labour market status each quarter.

The gross flow into unemployment, at just over 1 million, is broadly the same as a year ago.

The total unemployment outflow is lower than a year ago.

The gross flow into employment in the latest quarter is lower than a year ago.

The gross flow into inactivity is broadly the same as a year ago, but the gross outflow from inactivity is lower than a year ago.

\section{Quarterly gross flows}

The diagram below shows the gross flow between each economic status between April-June 2011 and July-September 2011. The stocks for each status represent the latter period and are the nonseasonally adjusted aggregates for people aged 16-64. 


\section{Quarterly population gross flow}

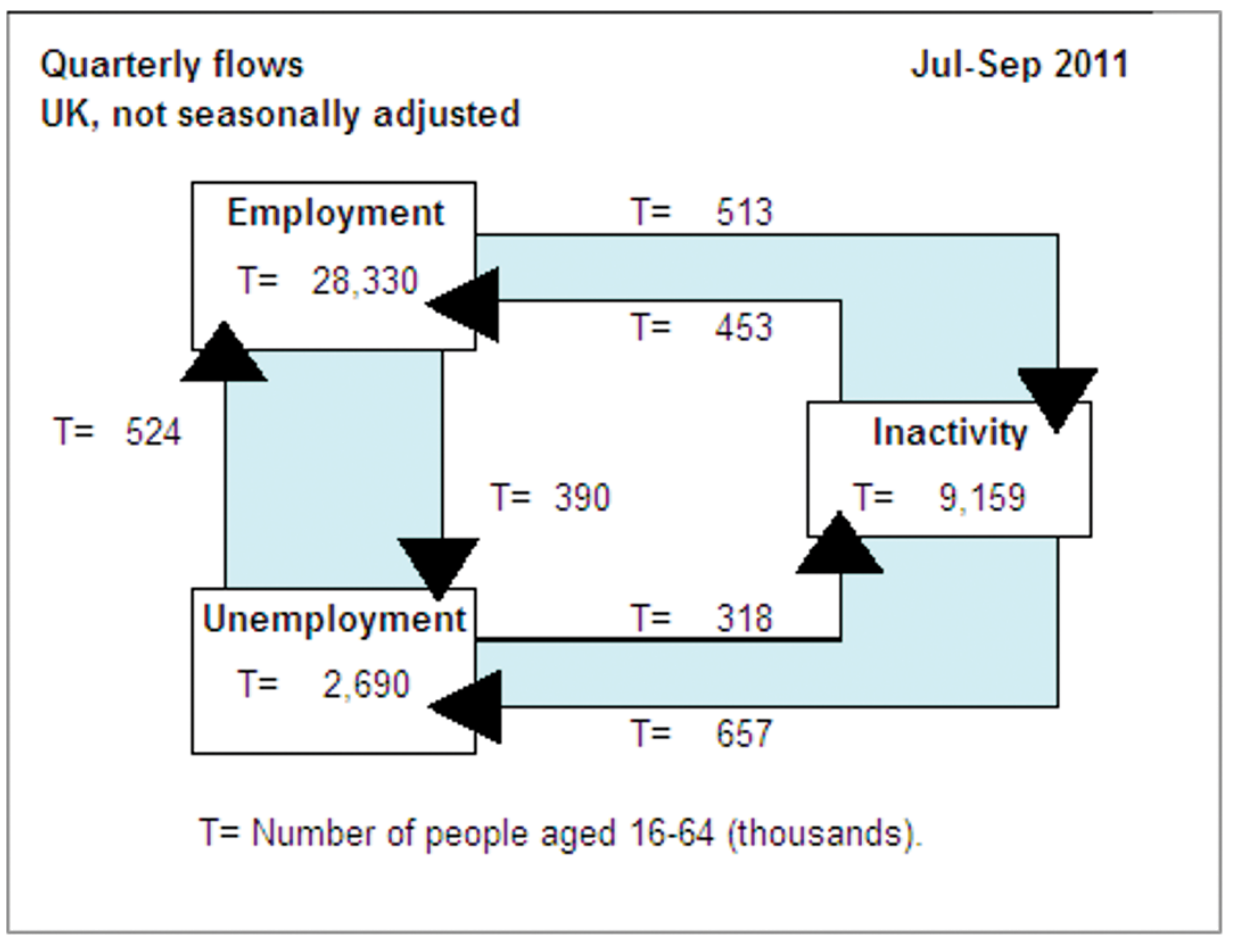

Source: Labour Force Survey - Office for National Statistics

\section{Download chart}

\section{XLS XLS format}

$(41 \mathrm{~Kb})$

We welcome feedback on the presentation of longitudinal data and how this can help illustrate complex changes in the labour market. Please forward any comments or queries to: Nick Palmer (tel: 01633 455839, email: nicholas.palmer@ons.gov.uk)

\section{Unemployment}

Gross inflow to unemployment (chart 1) is broadly the same as a year ago. The sharp increase from quarter 32008 onwards was due to the flow from employment. However, since quarter 32009 this has abated. The flow from inactivity has been on an upward trend since 2006 and is now driving the gross flow. 


\section{Chart 1: Inflow to Unemployment (16-64)}

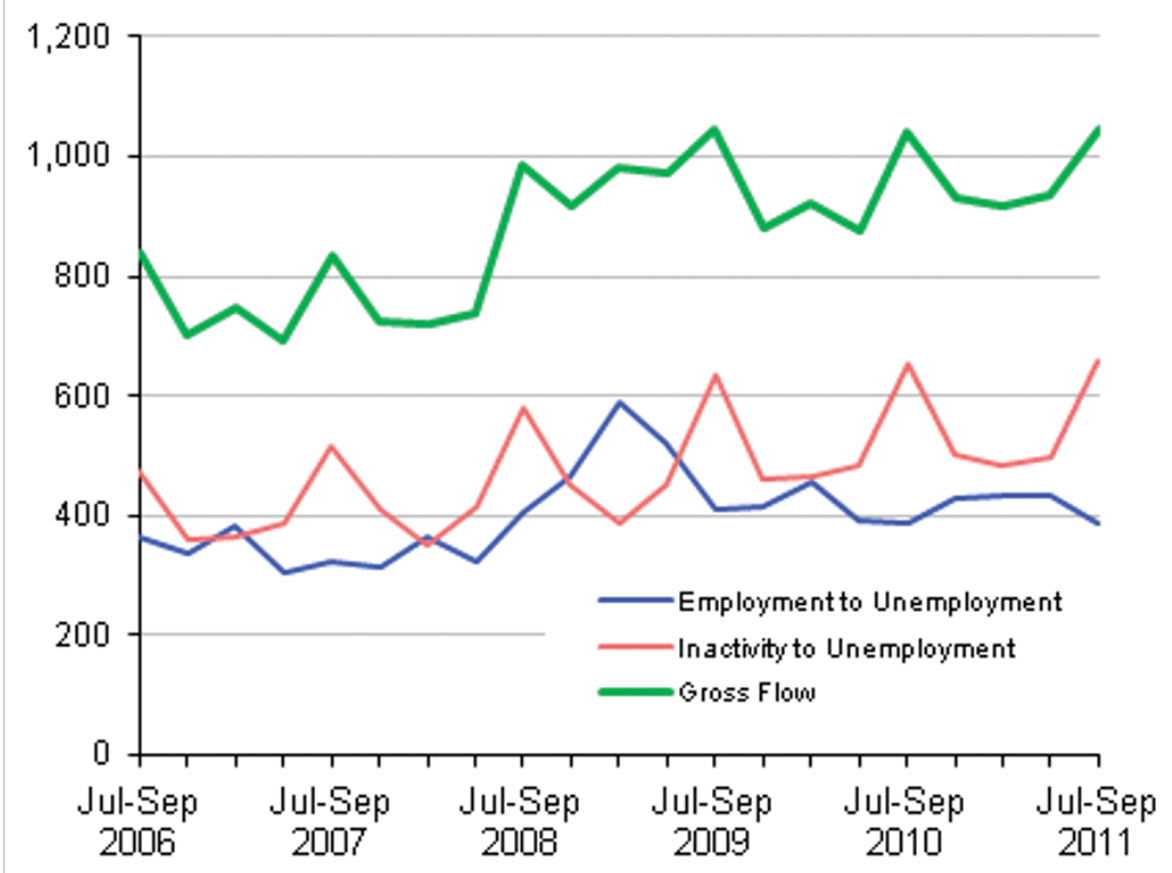

Source: Labour Force Survey - Office for National Statistics

\section{Download chart}

\section{XLS XLS format}

$(41 \mathrm{~Kb})$

The gross outflow from unemployment (chart 2) is lower than a year ago. The flows to employment and to inactivity have decreased over the year. 


\section{Chart 2: Outflow from Unemployment (16-64)}

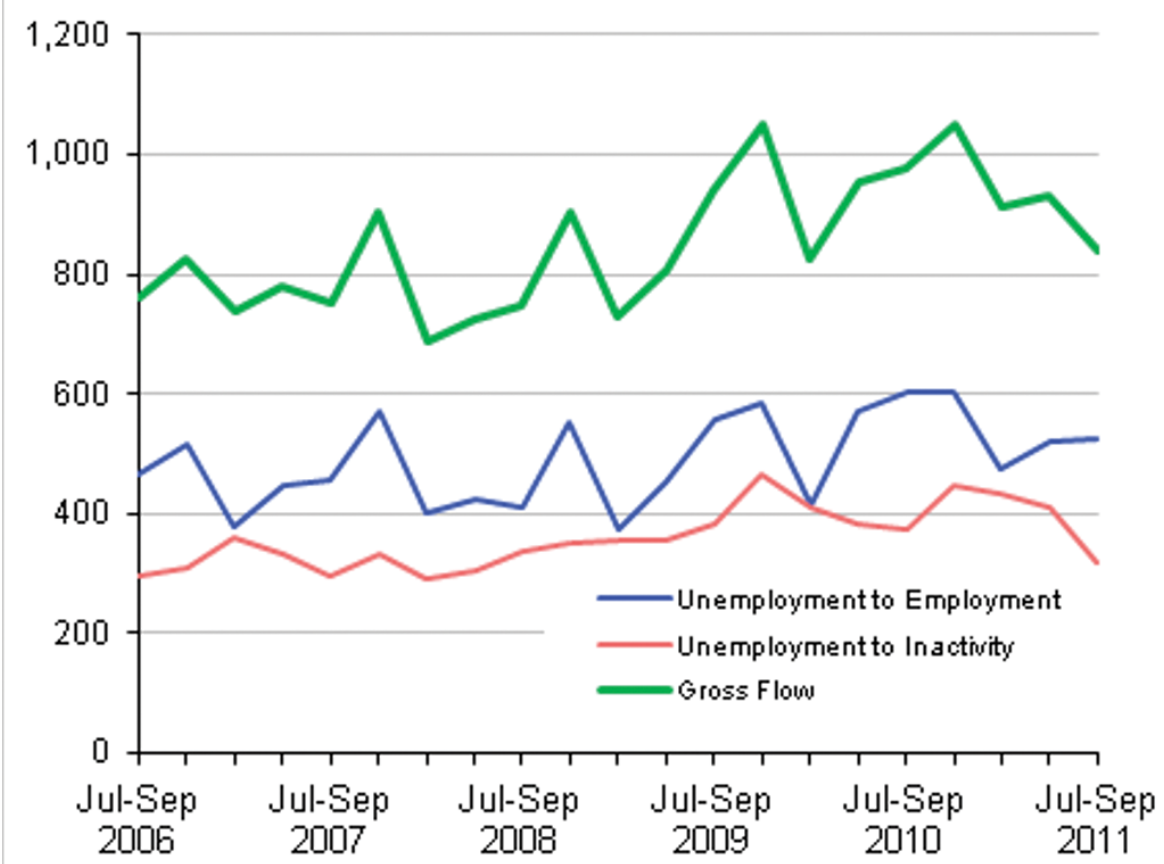

Source: Labour Force Survey - Office for National Statistics

\section{Download chart}

\section{XLS XLS format}

$(41 \mathrm{~Kb})$

Chart 3 shows the net flow in quarter 32011 is higher than a year ago and it is around 200,000 higher than in quarter 22011 . As the chart shows, the unemployment net flow tracks the quarterly changes in the published stock levels. 
Chart 3: 16-64 Unemployment: Net Flow vs Change in Stock (NSA)

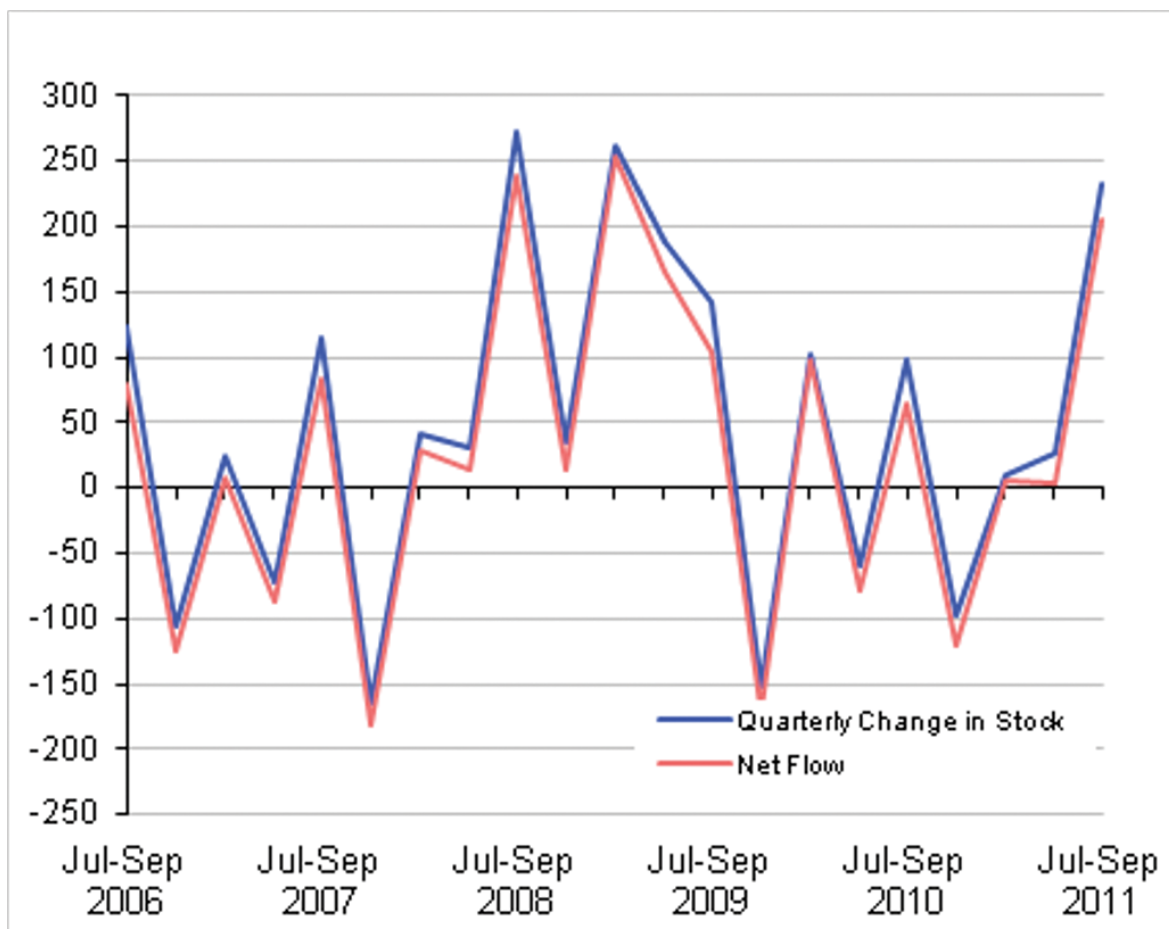

Source: Labour Force Survey - Office for National Statistics

\section{Download chart}

\section{XLS XLS format}

$(41 \mathrm{~Kb})$

\section{Employment}

The inflows to employment (chart 4) from both inactivity and unemployment have decreased in comparison with the previous year. 


\section{Chart 4: Inflow to Employment (16-64)}

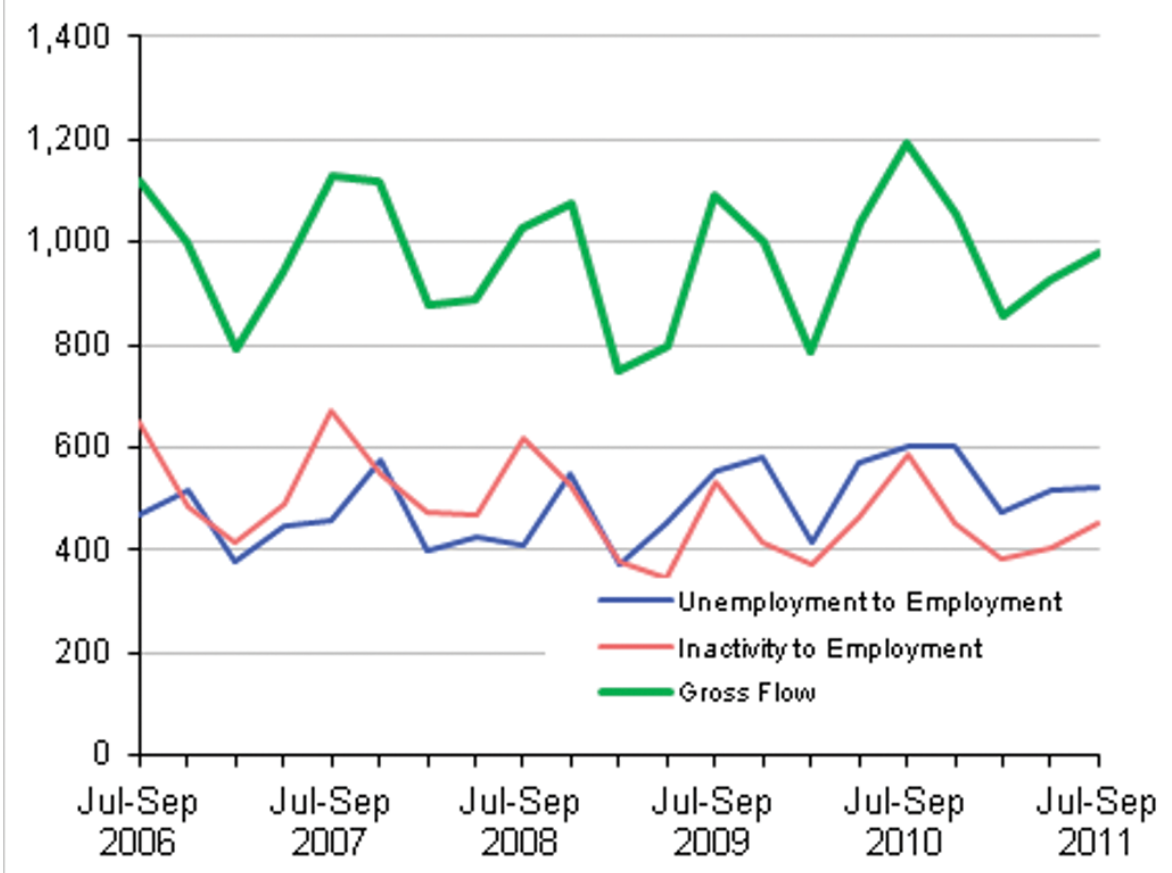

Source: Labour Force Survey - Office for National Statistics

\section{Download chart}

\section{XLS XLS format}

$(41 \mathrm{~Kb})$

The total outflow from employment (chart 5) shows an increase on a year ago. The outflow to unemployment is broadly the same as a year ago. The outflow to inactivity has increased over the year. 


\section{Chart 5: Outflow from Employment (16-64)}

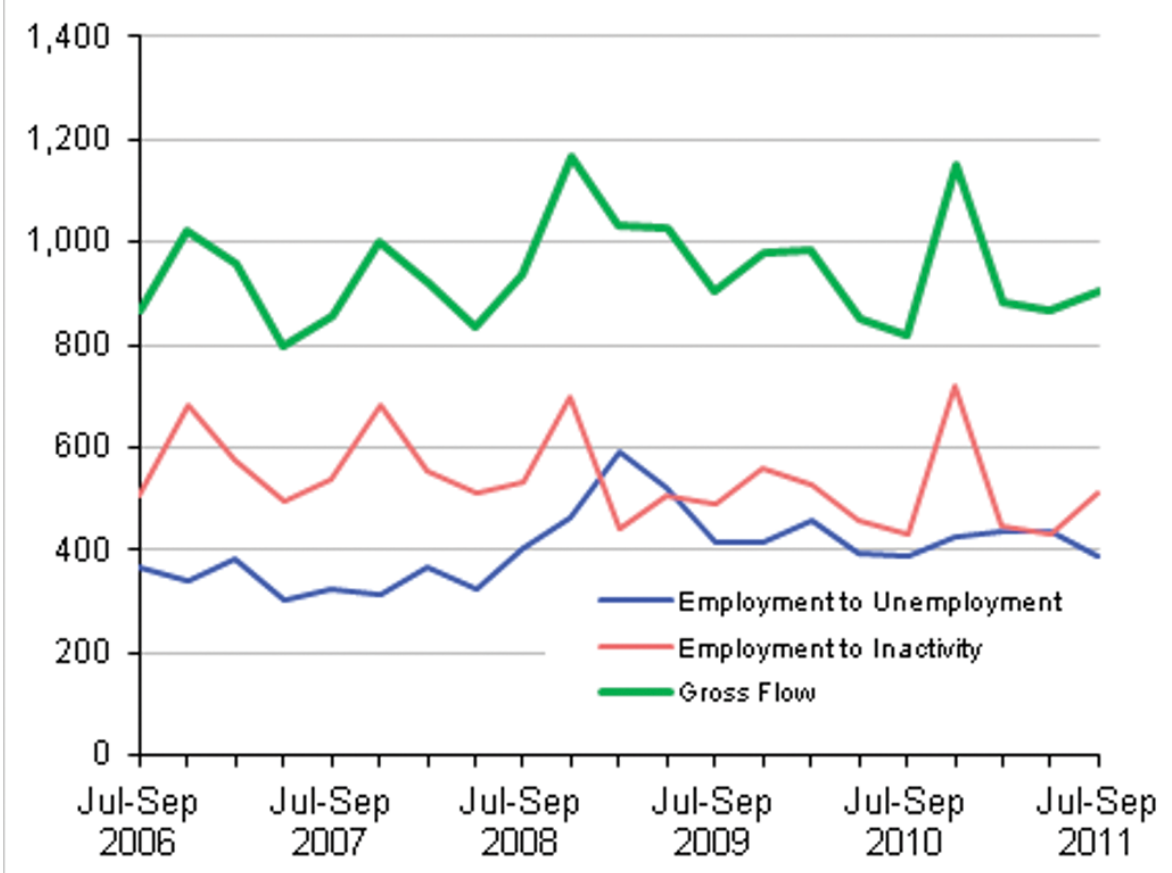

Source: Labour Force Survey - Office for National Statistics

\section{Download chart}

\section{XLS XLS format}

$(41 \mathrm{~Kb})$

The net flow for employment (chart 6) is positive in quarter 32011 but it is still lower than in quarter 32010 and quarter 32009 . As the chart shows the employment net flow tracks the quarterly changes in the published aggregate. 
Chart 6: 16-64 Employment: Net Flow vs Change in Stock (NSA)

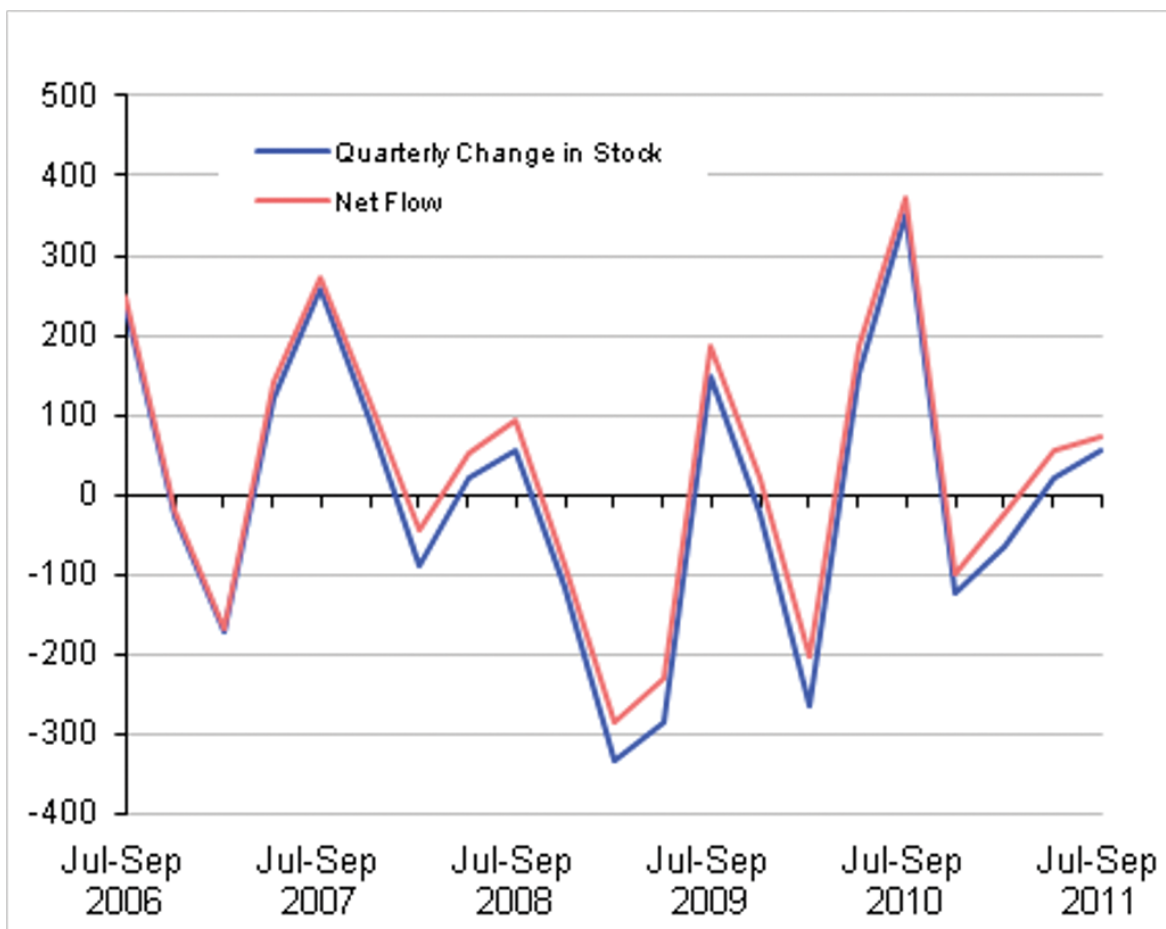

Source: Labour Force Survey - Office for National Statistics

\section{Download chart}

XLS XLS format

$(41 \mathrm{~Kb})$

\section{Inactivity}

The gross inflow to inactivity (chart 7) in quarter 32011 is broadly the same as a year ago. The inflow to inactivity from unemployment is lower than a year ago and inflow to inactivity from employment is higher than a year ago. 


\section{Chart 7: Inflow to Inactivity (16-64)}

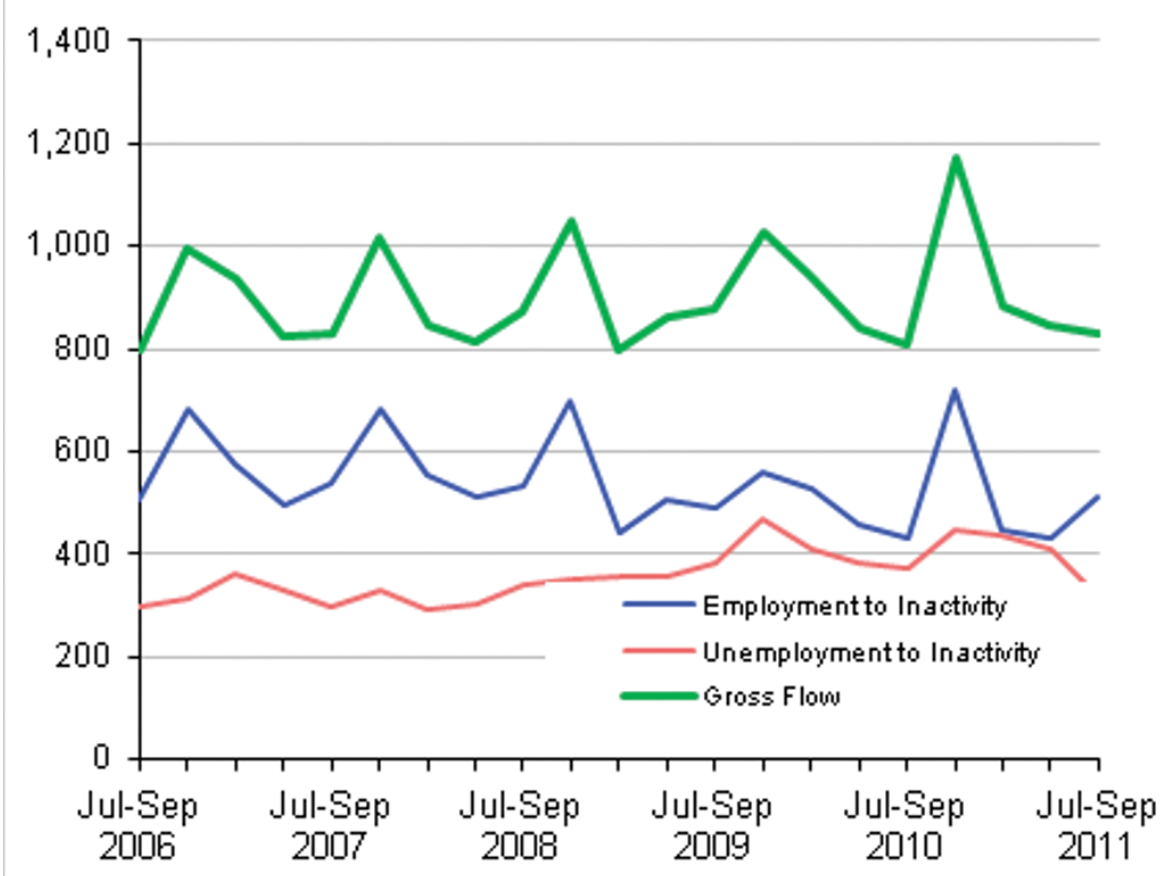

Source: Labour Force Survey - Office for National Statistics

\section{Download chart}

\section{XLS XLS format}

$(41 \mathrm{~Kb})$

The total outflow from inactivity (chart 8) in quarter 32011 is lower than a year ago. Outflow to unemployment is broadly the same as a year ago and now is driving the overall outflow, rather than the flow to employment, as in the past. 


\section{Chart 8: Outflow from Inactivity (16-64)}

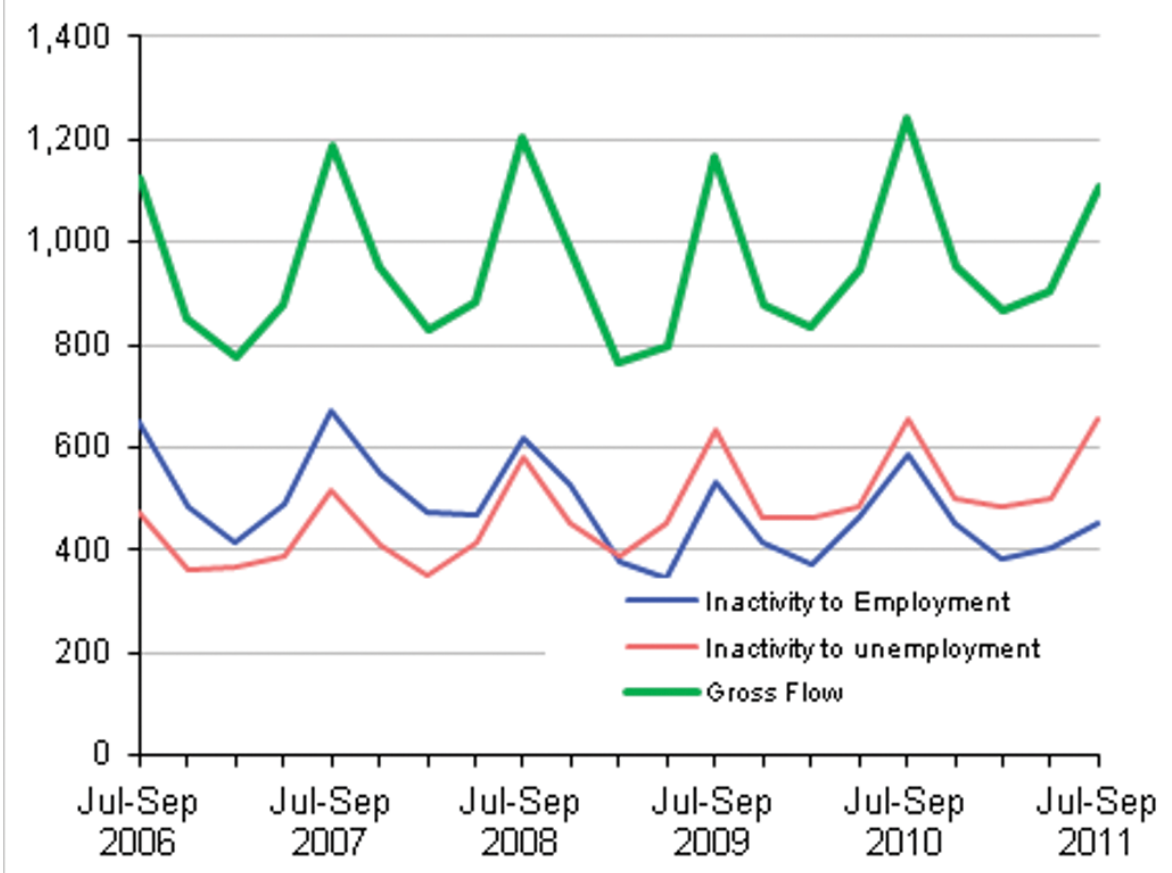

Source: Labour Force Survey - Office for National Statistics

\section{Download chart}

\section{XLS XLS format}

$(41 \mathrm{~Kb})$

Chart 9 indicates that the difference between the net flow and quarterly change in stock is very small in quarter 3 2011. These differences are explained in technical note point 3. 


\section{Chart 9: 16-64 Inactivity: Net Flow vs Change in Stock (NSA)}

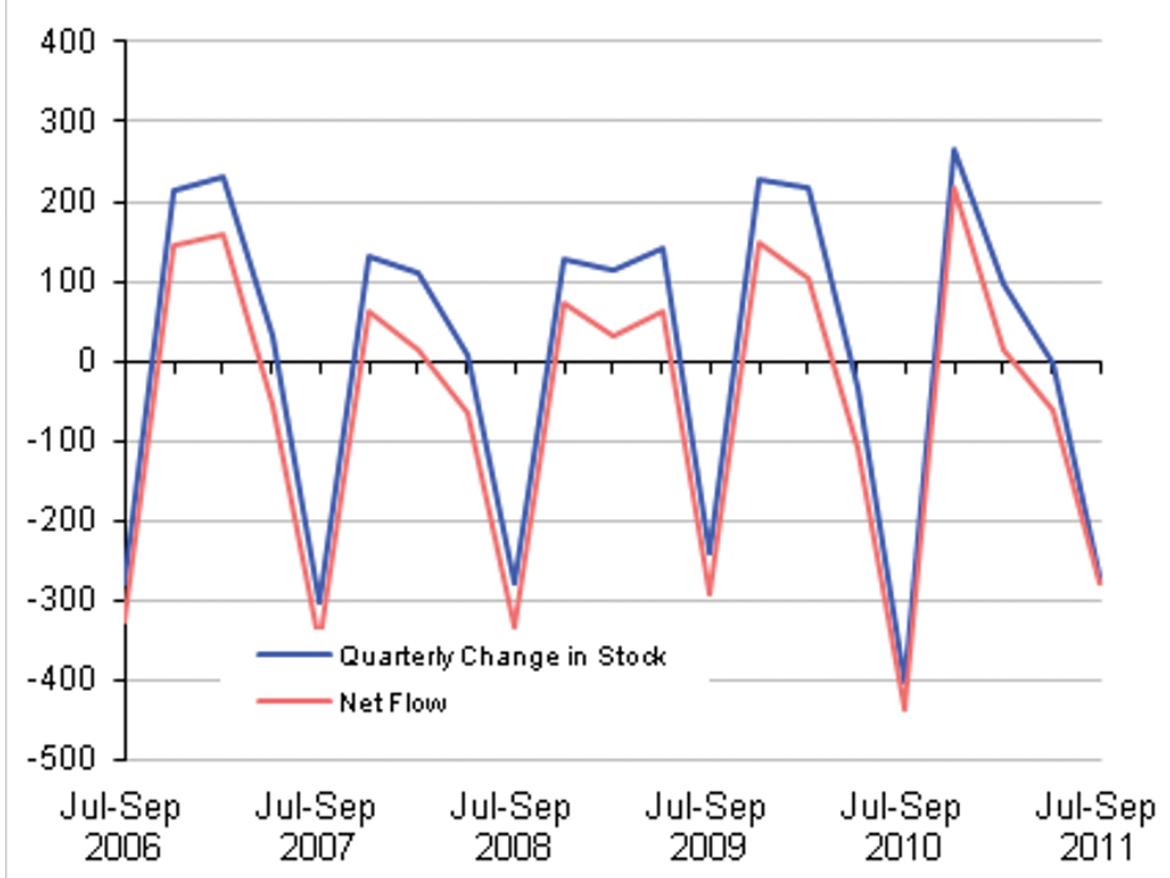

Source: Labour Force Survey - Office for National Statistics

\section{Download chart}

\section{XLS XLS format}

$(41 \mathrm{~Kb})$

\section{Technical Note}

There are differences between the data used for the published LFS aggregate estimates and the longitudinal data used to estimate the gross flows:

1. Flows are currently adjusted for non-response bias through special calibration weights in the longitudinal datasets. These aim to account for the propensity of certain types of people to drop out of the LFS between one quarter and the next. For example, housing tenure features in the weighting of the longitudinal data because, historically, households in rented accommodation have been more likely to drop out of the survey than owner-occupiers.

2. There is some evidence that the longitudinal datasets are affected slightly by response error which causes a slight upward bias in the estimates of the gross flows. For example, if it was erroneously reported that someone had moved from unemployment to employment then, in addition to the outflow from unemployment being overestimated, so would the inflow to employment. In the main quarterly LFS dataset, any such miss-reporting errors tend to cancel each other out.

3. The differences in the net flows for inactivity shown in Chart 9 are mainly the result of excluding the entrants to, and leavers from, the population in the flows estimates contained in this piece of analysis. This effect is normally one that increases the number of people who enter inactivity. This is because the increase in inactivity from those people turning 16 is greater than those leaving inactivity due to becoming 65. 
4. The stocks derived from the longitudinal datasets differ from those obtained from the quarterly LFS datasets due to their being based on a subset of the main LFS sample. The restriction to measuring only those who are commonly aged 16-64 across successive quarters discounts those entering or leaving the population and also those over 64. All such people are accounted for in the headline LFS aggregates.

\section{References}

1. Jenkins J and Chandler M (2010) 'Labour market gross flows data from the Labour Force Survey’ Economic \& Labour Market Review, February 2010. 